Broto, VC; Boyd, E; Ensor, J; (2015) Participatory urban planning for climate change adaptation in coastal cities: Lessons from a pilot experience in Maputo, Mozambique. Current Opinion in Environmental Sustainability , 13 11 - 18. $\underline{10.1016 / j . c o s u s t .2014 .12 .005 .}$.

\title{
Article
}

\section{Participatory urban planning for climate change adaptation in coastal cities: lessons from a pilot experience in Maputo, Mozambique}

Vanesa Castán Broto, Bartlett Development Planning Unit, UCL

Emily Boyd, Geography and Environmental Science, Reading University Jonathan Ensor, Stockholm Environment Institute, University of York

\section{Acknowledgements:}

We wish to thank all the people that supported this work in Maputo, and specially Charlotte Allen, Julio Parruque, Carlos Seventine, Domingos Augusto Macucule, David Nhancale and Felisbela Materula. Thanks to David Simon and Hayley Leck for their encouragement and editorial suggestions. We would also like to thank the reviewers for their comments. Part of this research was funded by the Climate Development Knowledge Network. A disclaimer applies. 


\section{Introduction}

The report of the 2014 IPCC Working Group II (Impacts, Adaptation and Vulnerability) includes a chapter on urban areas highlighting that action for effective urban adaptation is both urgent and feasible [1]. Following calls to recognise the role of cities in climate change [2-4], the Ad Hoc Working Group on the Durban Platform for Enhanced Action (ADP) (the group working on a legally binding agreement under the United Nations Framework Convention on Climate Change (UNFCCC) applicable to all Parties no later than 2015) requested the constitution of the Forum on Cities and Subnationals (henceforth the Forum) at the UNFCCC Warsaw COP in November 2013. The Forum's main objective is to track the emerging opportunities for climate change adaptation and mitigation within cities and sub-national regions.

In its meeting at the UNFCCC in Bonn in June 2014, the Forum highlighted the importance of engaging citizens in participatory urban planning processes [5]. For those in attendance, the Forum transmitted a sense of 'collective aspiration' that, in cities, is fostered through the active exercise of citizenship. There were calls for moving away from an instrumental understanding of participatory urban planning as a means to extract information on citizens' aspirations locally, seeking instead to promote participation in urban planning as a means to advance the rights of those urban citizens who are most vulnerable to climate change.

Calls for participation go hand in hand with a realisation that urban planning is a key mechanism to deliver effective climate change action. Planning emerges as a means to address structural vulnerabilities in urban areas, highlighting the interrelationship between climate change vulnerabilities and other aspects of the urban condition, such as poverty, inequalities, livelihood means and access to services [6-8]. The chapter on urban areas of the 2014 IPCC working group II argues that effective urban adaptation strategies require local governments to work in partnership with low-income groups and vulnerable communities $[1,9,10]$. Participatory urban planning can also be a means to build such partnerships alongside other forms of cooperation at different levels of decision-making [11]. Overall participatory urban planning emerges both as a framework for collective action to advance citizens' rights and as a mechanism to establish deliberative institutions in which multiple concerns can be heard and acted upon.

This paper offers an appraisal of participatory urban planning for adaptation in practice, building upon a participatory experience in the neighbourhood of Chamanculo $\mathrm{C}$, in Maputo (Mozambique) between 2011 and 2013. This work has already been reported elsewhere $[7,12-14]$ but in this paper, the experience is reassessed in relation to recent debates in development planning within the framework of the ADP mandate. The paper is divided into three parts. The first section explores the concept of participation in environmental and climate change planning, with a focus on underserviced areas and informal settlements in coastal cities. The second section explains our proposal for participatory urban planning in practice, following our experiences in Maputo. Finally, the third section exposes some of the challenges that emerge to deliver a rights-based process of participatory urban planning. Overall, this assessment suggests that participatory urban planning can lead to effective action for climate change adaptation but there are challenges that can only be addressed within the specific context of communities and places.

\section{Planning and the adaptation challenge in coastal cities}

Research on climate risk has paid attention to cities in coastal areas both because of their exposure to sea level rise, flooding and cyclones and because they are often inhabited by vulnerable populations [15-17]. Urban planning is most often seen as a means to evaluate and address the complicated interactions between climate change mitigation and adaptation that emerge in coastal areas [18-20] 
The characteristics of coastal areas from Hat Yai in Thailand to Cartagena in Colombia have also provided spaces to experiment with participatory and community-based adaptation [2124]. This requires understanding the specific strategies that local people, over time, have developed to deal with the ongoing risks likely to be exacerbated by climate change $[25,26]$. This may also require a broader understanding of the factors that lead to lack of effective spatial planning strategies, particularly in poor and informal settlements along coastal areas which are regularly exposed to flooding [27]. The neglect of informal settlement dwellers is linked to the reproduction of vulnerabilities both within specific settlements and within the larger city, for example, when electricity cabling provokes blackouts [28]. These examples from recent literature- which follow a long and well established academic debate in development planning- emphasise the need to address climate change adaptation in relation to citizenship and collective rights.

Within development studies, the critique of participation has highlighted that participation is unable to deal with local inequalities and power relations and it does not constitute a challenge to the development imperatives that emerge from international political discourses and transnational economic interests [29]. Questions have been raised about the extent to which participatory processes enrol powerless people into development projects that they are unable to question and that obscure the motivations of development experts, often leading to a de-politisation of the development process itself [30]. Yet, this debate has led to a greater understanding of the motivations for participatory processes. Participation defendants have highlighted that this critique caricaturises the process of participation and overlooks the potential for empowerment that emerge in messy processes and political struggles across scales [31]. Participation can be conceptualised as an active form of citizenship or as a right to shape processes of development, rather than as an invitation from external actors to participate in them [32]. In an urban context, this form of participation is understood as a right. It emerges within ideas of the right to the city, that is, the multiple claims that arise from citizens who want to have a voice in the urbanisation process and how it happens, but who may be unable to put forward their visions within existing political constraints [33]. As a slogan firstly popularised by Henri Lefevbre, the idea of the right to the city evokes the possibilities for urban citizens to participate in the definition of their own futures $[34,35]$.

What does this mean in the context of planning for climate change adaptation? Recent empirical studies have continued to track sophisticated ways in which dominant discourses of modernisation and capital-led development are imposed through participatory processes $[36,37]$. Experiences of community-based adaptation demonstrate that participatory processes may fail to deliver outcomes that effectively improve the lives of the urban poor [38]. Despite these challenges, however, there is a continued call for participation in climate change adaptation planning. There is an instrumental motivation for this: that, despite its challenges, participatory urban planning emerges as a solution to the challenges posed by enforcing top-down forms of planning, particularly in cities in which governments lack governance capacity. There is another motivation that emerges from a rights-based perspective: the idea that climate change adaptation constitutes an opportunity to address structural vulnerabilities in relation to service provision, economic inequalities and access to policy making. Avoiding the pitfalls mentioned above will require moving away from the first to the second motivation, to ensure that participatory urban planning focuses on advancing citizens' rights, rather than consolidating the powers of a state that fails to recognise or support their needs.

Ultimately, participatory urban planning is not a silver bullet that will provide a sanitised and uniform solution to climate change action, but rather, it is a messy and open-ended process that seeks to decentralise power by emphasising the co-construction of knowledge for planning, beyond the sanctioned centres of knowledge production in academia and consultancies. It is, however, a process that cannot be separated from local politics, and 
which could be opened to elite capture. But it is also a process that adopts a language of citizen rights explicitly and in that manner, seeks to bring future visions from the bottom up. The literature above shows the importance of: 1) understanding structural inequalities; 2) gaining, even if temporarily, institutional support to legitimise and sustain the process; and 3) delivering a practical process of participation in constant negotiation with local actors, not just in terms of what the outcomes of the process should be but in terms of how they can shape the process itself to try to ensure that it helps them advance their claims.

\section{Participatory urban planning for climate change adaptation in Maputo, Mozambique}

Our approach to participatory urban planning emerges from a three-year engagement with an action-research project in Maputo where we set out to deliver local climate change and development plans. In this engagement, we adapted an approach to adaptation planning proposed by one of the authors [39], in which deliberate emphasis is placed on rights-based participation to provide the conditions for collective action. We assumed that collective action depended on the recognition of these rights by local institutions and the co-production of knowledge among many actors within and beyond the community, such as scientists, officials, NGO workers, activists, planners, local businesses, and citizens. Another innovative aspect in this project was the incorporation of highly technical knowledge from climate scenarios in participatory discussions to mediate local and place-based understandings of climate change risks. Finally, we worked closely with local mediators who had experience in local planning processes and could negotiate the politics of urban planning for adaptation.

The city of Maputo is divided between the cement city, which has evolved from the colonial city built by the Portuguese, and the surrounding bairros, mostly informal settlements, in which the majority of the people live. We focused in one of these bairros, Chamanculo $\mathrm{C}$, which has been hit severely by previous flooding events. This section follows the conceptual framework advanced in the previous section, exploring three aspects of participatory urban planning: 1) the identification of structural vulnerabilities in Chamanculo $C$; 2) the establishment of a dialogue with local institutions to develop partnerships for climate change; and 3 ) the implementation of a participatory urban planning process with climate change at its centre.

\section{Context of vulnerability in Maputo}

The metropolitan area of Greater Maputo is the most densely populated area in Mozambique. Mozambique is highly vulnerable to natural disasters, in particular those of hydro-meteorological origin such as floods, drought and cyclones. Climate change will contribute to the uninterrupted sequence of drought and floods that Mozambique has suffered from since 1970, with devastating social and economic consequences [40,41]. In the city of Maputo, the main hazards associated with climate change are likely to be temperature increases, extreme events related to precipitation and sea level rise. There are already noticeable coastal erosion problems, but further sea level rise will increase the risk of flooding in the lowest topographical areas [42,38]. The potential impacts of extreme events in Maputo are likely to be associated with the deterioration of an already precarious infrastructure system, food insecurity and the increase of vector-borne diseases.

The impacts of climate change need to be understood in the context of vulnerability in the city of Maputo [7]. Approximately 54\% of Maputo City's residents live below the poverty line of $\$ 1.50$ per day and $70 \%$ live in informal settlements and areas of dense unregulated growth which lack common infrastructure services such as water, sanitation, drainage and electricity [42]. Government authorities and expert assessments link vulnerability to floods to a proliferation of unplanned human settlements during the last three decades, which has gradually expanded to topographically depressed and marshy areas characterised as exposed to high flood risk. Chamanculo is an historical bairro built in a flood-prone area.

More than $60 \%$ of the population in Maputo has limited access to services such as energy, cooking fuel and sanitation [43]: access to services and infrastructure constitutes one of the 
main aspects of urban deprivation in Maputo. This is especially important in informal settlements where sanitation and drainage is often very poor. A study found that $33 \%$ of households have only a simple pit latrine, which can lead to serious health issues following flash floods [44].

In Chamanculo C, vulnerability is closely linked to poverty and limited access to resources, the characteristics of the soil (their compaction and limited capacity to infiltrate water), the coverage of built up and paved surfaces, deficient drainage and the extent to which the tree canopy supports infiltration. One important vulnerability factor is the presence of a waste dumps, often 5 to 15 meters in height and completely surrounded by houses, which may increase run off, blockage of drains and introduce contamination of living spaces with potential detrimental health effects.

\section{Institutional support for participatory urban planning}

To gain institutional support, in consultation with informants in different government and civil society organisations, we focused on the municipality (the Conselho Municipal) as the key institution that can respond directly to the needs of citizens. However, the municipality faces difficult dilemmas in urban adaptation planning. The municipality has worked with UN-Habitat and the National Institute for Disaster Management (INGC) on an assessment of the possible impacts of climate change throughout the city and ecological zoning of the mangrove swamp in Costa do Sol, on the east of the city overlooking the Indian Ocean. Meanwhile, some citizens have raised concerns about the extent to which these planning practices have allowed the construction of luxury houses in highly desirable areas where the mangroves are situated. These debates reveal the complex set of circumstances in which municipal decisions are taken and the limited extent to which mechanisms such as zoning can actually be enforced.

In this context, there have been efforts within the municipality to improve ongoing dialogue with communities particularly on issues that affect them directly, such as solid waste management. For example, NGOs such as Engineers without Borders have mediated a partnership between the municipality and local waste pickers called 'catadores' who can access informal areas more easily. This has improved waste management in many bairros considerably.

Previous experiences of partnerships for waste management and water provision suggest that there is great potential for partnerships that involve communities in decision making for climate change action [12]. However, this potential is also mediated by the political economies of urban development and the extent to which local officials are able or willing to control the construction of luxury residences and businesses in areas at risk of flooding while also providing services to already existing informal settlements. In Chamanculo $\mathrm{C}$, for example, local residents and stakeholders highlight the need to upgrade and re-order the city's inner unplanned bairros, to address the problems of providing public infrastructure and services. The lack of infrastructure already compromises the most basic services in Chamanculo C. Climate change will exacerbate this situation. Negotiating the political context may require not just claiming the rights of citizens living in informal settlements but also demonstrating how city officials could address these claims. Moreover, municipal officials do not act in a vacuum. Multiple actors may mediate the actual impacts of climate change action, including NGOs, national and international organizations. This is a mere overview of the complex dilemmas that emerge and need to be negotiated during any process of participatory urban planning. In this context, climate change, and its potential impacts through flooding, provides a discourse around which multiple contexts can coalesce, provided that it is clearly linked to local development priorities.

\section{Participatory Action Plan Development in Chamanculo C}

In this project we adapted a participatory methodology called Participatory Action Plan Development (PAPD) with an aim to foster negotiation and dialogue, leading to knowledge co-production $[45,46]$ and collective action. PAPD was originally developed for use with 
marginalised communities, with the intention to build new political and institutional relationships. The focus of PAPD is on how power relations shape local development opportunities and, in this context, how to develop the conditions for power sharing between citizens and the institutions and interests that influence their lives. PAPD is oriented towards building a consensus about development priorities in a given area. This refers to consensus not just in relation to what decision should be taken but also, in relation to how such decisions are taken. Thus, the PAPD methodology provides opportunities both to deliberate about local development priorities and to build capacity to present such proposals to city actors that can help achieving them. In this context, 'consensus' implies a negotiated agreement in which all stakeholders are satisfied with the outcome at a given moment. While this does not require total agreement, it does bring all stakeholders to the point where none have concerns or objections that they feel are significant enough to justify blocking the shared wishes of the whole group. This also means that local facilitators are needed to focus discussions around areas of common concern. Facilitators may need to shift the topic of conversation away from contentious issues to break deadlocks. This means that not all the topics are suitable for negotiation through this methodology.

In Chamanculo C, the PAPD process was structured around the following steps:

- Step 1. Understanding differences in Chamanculo C. Different social groups were identified according to: (i) degree of inclusion in decision making (not to focus only on vulnerable groups, but to find both the powerful and less powerful), and (ii) different risks from or impacts of flooding. Identification of different social groups ensured perspectives on flooding that exist within the community were represented in the planning process (while accepting that there may be diversity of views within groups).This step took approximately three months, including consultations with community representatives and members of relevant organizations such as INGC and the Municipality.

- Step 2a. Community problem definition in facilitated meetings. Using flooding as an entry point to discussions of climate change, facilitators drew out perspectives on the problem of flooding, and views on potential ways of dealing these issues. Discussions were structured to explore (i) current understandings of flooding, and (ii) how this understanding may alter if floods were to be more extreme (linked to climate projections). Each group developed different proposals in weekly discussions that took approximately three months.

- Step 2b. Each group reported its findings to a plenary meeting of all groups. A facilitated discussion achieved broad agreement on the most significant challenges facing the community, and possible solutions. Facilitation was needed to focus the discussion on productive agreements. After this discussion, a 'Climate Planning Committee' (CPC) was elected, with one representative from each group.

- Step 3. Information gathering and engagement with secondary stakeholders. The CPC worked on the development of the proposals during three months in which they presented the output of Step $2 b$ to representatives from NGOs and the municipality to compile information about their feasibility and sustainability. The groups were then reconvened in a plenary meeting for a facilitated discussion around the potential and limitations of their proposals, and any new information received, to arrive at a fuller and more nuanced set of proposals. From this basis the CPC prepared a draft plan.

- Step 4. Open community meeting. Attended by the wider community, an open meeting discussed and provided feedback and local validation of the draft plan. The 
open community meeting took place in May 2012, approximately six months after the beginning of the participatory process.

- Step 5. Final workshop. In a final and highly effective step, the CPC presented the community diagnosis and plan to donors, municipality officers and elected members, and other stakeholders in adaptation planning including UN Habitat. This 'learning workshop' took place in June 2012. Following discussion, breakout sessions divided the participants into cross-sectoral teams to identify practical next steps in implementation of the plan. A new open community meeting took place after the workshop in June, and the CPC continued to meet with secondary stakeholders to start the road towards the implementation of proposals.

These steps illustrate how participatory urban planning in Chamanculo $\mathrm{C}$ focused not just on identifying local development priorities, but also, on fostering institutional mechanisms that could support the communication of such priorities. The institution of a CPC of elected members across the community was subsequently followed by an active engagement process in which CPC members took strong leadership in engaging with relevant stakeholders, developing detailed proposals and working on a road map towards implementation. Ultimately, they prepared a local action plan as an instrument for negotiation. This was a tangible output that was shared across stakeholders and has helped to build a consensus about key development interventions which would benefit the bairro. The research team facilitated the communication of climate change information in the context of Maputo with a double strategy of relating climate change to previous experiences of flooding and disasters in the Chamanculo $\mathrm{C}$ while linking the information to development priorities. This information constituted the backbone of the evidence that the community representatives presented in the local action plan.

Their proposals included to start a process of negotiation with the local water companyFIPAG- to improve the provision of water and its maintenance; a partnership between the CPC and the National Fund for the Environment (FUNAB) to implement a plan for reduction of waste in the neighbourhood; and a community proposal for the development of endogenous environmental knowledge through theatre, films and workshops that could foster collective action within the community to clean drains. Other ideas have emerged since the constitution of the CPC in relation to improving access roads and understanding the local energy supplies but it is still early days to evaluate the whole impact in the neighbourhood. Above all, the process of participatory urban planning has enabled local residents to formally reject the proposals for relocation that have been previously floated by both municipal and national government representatives and which most members in the community consider not to be viable.

The process, however, also entailed certain compromises to make it practicable and navigate the local politics, including gaining the support of the bairro secretary and local chiefs. Community profiling led to the establishment of sub-groups that worked independently during the PAPD, representing varied interests including those of the elderly, youth, women who lacked employment, people who worked in small business and salaried workers. Each group had different concerns in relation to their demands for services and mobility; but despite their interests they were able to engage in a group discussion that was later shared collectively with other community members.

In Chamanculo $\mathrm{C}$, and more generally in Maputo, climate change is a collective problem and its stakes are shared by many actors. Local residents gained confidence in their perspectives and the CPC led a learning workshop to present their views to a wider audience of higher level institutional representatives and policy makers. The project created a shift away from having local residents participating in planning for their neighbourhood to actively leading and mediating a planning process. 


\section{Conclusion}

\section{Emerging challenges for participatory urban planning in practice}

The example in Chamanculo $\mathrm{C}$ suggests that participatory urban planning has a role in tackling climate change challenges in coastal cities. Three lessons emerge in relation to the theoretical discussion above. First, the process led to a better understanding of structural inequalities in relation to climate change but there were challenges in understanding the relevance of climate change information at the neighbourhood level. Second, government organisations, especially FUNAB, provided institutional support to sustain the process, but this support dwindled after the project finished. Finally, there has been an impasse between the definition of community proposals and their implementation. Some of the proposals may never been implemented, at least not in the original form in which they were conceived.

In relation to the co-production of knowledge, our experience suggests that local people can meaningfully engage with technical knowledge, contributing to the literature that highlights knowledge co-production strategies as central for sustainable development $[47,48]$. Particularly with regards to current and future impacts, they can engage with different climate change scenarios by relating these to their own experiences. Empirical research in Maputo and elsewhere demonstrates that, like institutions, low income communities also learn practical ways to deal with climate change impacts from previous events such as flooding [see also 49].

However, the main challenge in terms of knowledge production remains in relation to the representation of science in the scenario process. Because of the background and knowledge of the research team, we focused on bringing information from climate change models, but could not include the full range of data available at local and regional scales, and the interaction of this data with urban systems more broadly. Here, local institutions such as the INGC can provide crucial insights by drawing on data available locally and make it easily accessible to the communities involved in participatory urban planning processes.

The second challenge relates to the extent to which participatory urban processes receive enough support and attention from relevant government organisations and institutions. For participatory urban planning to progress and have an impact, an appropriate process of institutional support needs to be in place [14]. The local government, in particular, is often described as the most relevant in participatory urban planning, because local governments can support this process directly and can incorporate citizens' recommendations in planning guidance and other local-based interventions for climate change. Yet, the difficulties that local governments face both to integrate climate change knowledge and to deliver adaptive action are well documented $[50,51]$.

In Africa, there is recognition that local governments most often lack the capacity to deliver basic services, which makes it difficult to improve processes of planning and governance [52]. Successful climate change action depends heavily on the ability of key actors to form alliances capable of linking knowledge and institutional support to enable effective climate change action [as shown in 11,53]. Thus, participatory urban planning is both a means to empower citizens to play a part in defining rights to an urban future and a means to provide access to otherwise absent services. The risk here is that participatory urban planning also becomes a means to transfer responsibility for service provision from the state to citizens. For example, the process in Chamanculo $\mathrm{C}$ emphasised the need to involve the community in drainage cleaning, a function that in other places of the world would be fulfilled by the state. Simultaneously, the process also highlighted the responsibilities of the water company, FIPAG. Participatory urban planning is an open ended process in which agreement has to emerge from within the parts involved, but broader structural analysis may show whether it actually leads to just outcomes. 
The third challenge relates to measuring the impact of participatory planning. Locally, impact is related to the implementation of local strategies. However, the timescales of development are longer than those of participatory urban planning, and this may lead to loss of momentum within the community. In Chamanculo $\mathrm{C}$ action did not follow the immediate presentation of the plan in June 2013 because of bureaucratic obstacles, namely, potential partners could only work with formally constituted organisations. During the year following the presentation of the plan, the CPC worked to constitute the local association AMANDLA formally, and only in June 2014 could they start the negotiations for the establishment of a waste management centre formally. This raises questions about the need to formalise consensus and the extent to which this will be possible in every context.

Participatory urban planning constitutes an opportunity to build a form of planning from the bottom up which may lead to a more inclusive, and potentially fairer, society. However, participatory urban planning processes require a partnership built on mutual trust and understanding between local institutions and communities. This could be done, for example, by linking urban planning to a process of participatory budgeting with concrete resource allocations to the initiatives proposed by communities [54]. Nevertheless, participatory urban planning is not just directed towards resource allocation and that its main contribution may be the generation of evidence that identifies common stakes and shared responsibilities. This process may also produce concrete tools- e.g. a local action plan- for the community to negotiate their interests with other institutions and engage with climate change action in the long-term.

\section{References}

1. Revi A, Satterthwaite D, Aragón-Durand F, Corfee-Morlot J, Kiunsi RBR, Pelling M, Roberts D, Solecki W: Chapter 8: Urban areas. In Climate Change 2014: Impacts, Adaptation and Vulnerability, Contribution of Working Group II to the Fifth Assessment Report of the Intergovernmental Panel on Climate Change. Edited by IPCC: Cambridge University Press; 2014.

${ }^{* *} A$ landmark reading for anyone interested in climate change impacts, adaptation and vulnerability in urban areas.

2. Bulkeley $\mathrm{H}$ : Cities and the Governing of Climate Change. Annual Review of Environment and Resources 2010, 35:229-253.

3. UN-Habitat: Cities and Climate Change: Global Report on Human Settlements 2011. London: Earthscan; 2011.

4. Hoornweg D (Ed): Cities and Climate Change: Responding to an Urgent Agenda Washington DC: World Bank Publications; 2011.

5. Kacyira AK: Work plan on enhancing mitigation ambition forum on experiences and best practices of cities and subnational authorities in relation to adaptation and mitigation, Session on Tuesday. 10 June 2014, Summary by the Chair. Bonn: UNFCCC Secretariat; 2014.

6. Sanchez-Rodriguez R: Learning to adapt to climate change in urban areas. A review of recent contributions. Current Opinion in Environmental Sustainability 2009, 1:201-206.

7. Castán Broto V, Oballa B, Junior P: Governing climate change for a just city: challenges and lessons from Maputo, Mozambique. Local Environment 2013, 18:678-704.

8. Wilhelmi OV, Hayden $\mathrm{MH}$ : Connecting people and place: a new framework for reducing urban vulnerability to extreme heat. Environmental Research Letters 2010, 5:014021.

9. Revi A, Satterthwaite D, Aragón-Durand F, Corfee-Morlot J, Kiunsi RBR, Pelling M, Roberts D, Solecki W, Gajjar SP, Sverdlik A: Towards transformative adaptation 
in cities: the IPCC's Fifth Assessment. Environment and Urbanization 2014, 26:11-28.

10. Dodman D, Bicknell J, Satterthwaite D: Adapting Cities to Climate Change: Understanding and Addressing the Development Challenges. London: Routledge; 2012.

${ }^{* *} A$ key reading on participation and the role of local authorities which also provides an overview of climate change adaptation experiences in urban areas.

11. Leck H, Simon D: Fostering multiscalar collaboration and co-operation for effective governance of climate change adaptation. Urban Studies 2013, 50:1221-1238.

12. Castan Broto V, Macucule DA, Boyd E, Ensor J, Allen C: Building collaborative cartnerships for climate change action in Maputo, Mozambique. Environment and Planning $A$ forthcoming.

13. Castán Broto V: Viewpoint: Planning for climate change in the African city. International Development Planning Review 2014, 36:257-264.

14. Boyd E, Ensor J, Broto VC, Juhola S: Environmentalities of urban climate governance in Maputo, Mozambique. Global Environmental Change 2014, 26:140151.

15. McGranahan G, Balk D, Anderson B: The rising tide: assessing the risks of climate change and human settlements in low elevation coastal zones. Environment and Urbanization 2007, 19:17-37.

16. Nicholls RJ, Cazenave A: Sea-level rise and its impact on coastal zones. Science 2010, 328:1517-1520.

17. Rosenzweig C, Solecki WD, Blake R, Bowman M, Faris C, Gornitz V, Horton R, Jacob K, LeBlanc A, Leichenko R: Developing coastal adaptation to climate change in the New York City infrastructure-shed: process, approach, tools, and strategies. Climatic Change 2011, 106:93-127.

18. Nicholls RJ, Lowe JA: Benefits of mitigation of climate change for coastal areas. Global Environmental Change 2004, 14:229-244.

19. Viguié V, Hallegatte S: Trade-offs and synergies in urban climate policies. Nature Climate Change 2012, 2:334-337.

20. McEvoy D, Lindley $\mathrm{S}$, Handley $\mathrm{J}$ : Adaptation and mitigation in urban areas: synergies and conflicts. Proceedings of the ICE-Municipal Engineer 2006, 159:185-191.

21. Smith TF, Daffara P, O'Toole K, Matthews J, Thomsen DC, Inayatullah S, Fien J, Graymore M: A method for building community resilience to climate change in emerging coastal cities. Futures 2011, 43:673-679.

22. Bahadur A, Tanner T: Transformational resilience thinking: putting people, power and politics at the heart of urban climate resilience. Environment and Urbanization 2014, 26:200-214.

23. Stein A, Moser C: Asset planning for climate change adaptation: lessons from Cartagena, Colombia. Environment and Urbanization 2014, 26:166-183.

${ }^{* *}$ In this paper the asset planning framework is applied in planning for climate change adaptation.

24. Hardoy J, Hernández I, Pacheco JA, Sierra G: Institutionalizing climate change adaptation at municipal and state level in Chetumal and Quintana Roo, Mexico. Environment and Urbanization 2014, 26:69-85.

25. Wamsler C, Brink E: Moving beyond short-term coping and adaptation. Environment and Urbanization 2014, 26:86-111.

26. Haque AN, Dodman D, Hossain MM: Individual, communal and institutional responses to climate change by low-income households in Khulna, Bangladesh. Environment and Urbanization 2014, 26:112-129.

27. Kiunsi $\mathrm{R}$ : The constraints on climate change adaptation in a city with a large development deficit: the case of Dar es Salaam. Environment and Urbanization 2013, 25:321-337. 
28. Seeliger L, Turok I: Averting a downward spiral: building resilience in informal urban settlements through adaptive governance. Environment and Urbanization 2014, 26:184-199.

29. Mohan G, Stokke K: Participatory development and empowerment: the dangers of localism. Third World Quarterly 2000, 21:247-268.

30. Cooke B, Kothari U (eds.): Participation: The new tyranny? London: Zed Books; 2001.

31. Williams G: Towards a repoliticization of participatory development: political capabilities and spaces of empowerment. In Participation: From tyranny to transformation. Edited by Hickey S, Mohan G: Zed Books; 2004:92-109.

32. Gaventa J: Towards participatory governance: assessing the transformative possibilities. In Participation: From Tyranny to Transformation. Edited by Hickey S, Mohan G: Zed Books; 2004:25-41.

${ }^{* *} A$ well-loved classic arguing for a rights-based approach to participation. Widely used in development planning teaching.

33. Harvey D: The right to the city. International Journal of Urban and Regional Research 2003, 27:939-941.

34. Lefebvre H: The right to the city. In Writings on Cities. Edited by Kofman E, Lebas E: Wiley; 2002:86.

35. Brenner N, Marcuse P, Mayer M (eds.): Cities for People, not for Profit: Critical Urban Theory and the Right to the City. London: Routledge; 2011.

36. Taddei R: Watered-down democratization: modernization versus social participation in water management in Northeast Brazil. Agriculture and Human Values 2011, 28:109-121.

37. Li B: Governing urban climate change adaptation in China. Environment and Urbanization 2013, 25:413-427.

38. Dodman D, Mitlin D: Challenges for community-based adaptation: Discovering the potential for transformation. Journal of International Development 2013, 25:640659.

39. Ensor J: Uncertain Futures: Adapting Development to a Changing Climate. Rugby: Practical Action Publishing; 2011.

40. McBean G, Henstra D: Climate Change, Natural Hazards and Cities. In Research Paper Series n. 31. Toronto: Institute for Catastrophic Loss Reduction (ICLR); 2003.

41. Kundzewicz ZW, Budhakooncharoen S, Bronstert A, Hoff H, Lettenmaier D, Menzel L, Schulze R: Floods and Droughts: Coping with Variability and Climate Change. Bonn: International Conference on Freshwater: 2001.

42. MMC, UN-Habitat, Agriconsulting: Availação detalhada dos impactos resultantes dos eventos das mudanças climáticas no Município de Maputo. Nairobi: UN-Habitat; 2012.

43. Alkire S, Roche JM, Santos ME, Seth S: Mozambique Country Briefing. Oxford: Poverty \& Human Development Initiative (OPHI) Multidimensional Poverty Index Country Briefing Series. Available at:www.ophi.org.uk/policy/multidimensionalpoverty-index/mpi-country-briefings/. 2011.

44. Sollien SE, Andersen ABdC, Jenkins P: HomeSpace Maputo: Meanings and perceptions of the built environment in a rapidly expanding African City. In AEGIS - African Studies in Europe Conference. Uppsala; 2011.

${ }^{* *}$ This is just one of the outputs of the HomeSpace project, one of the most complete assessments of the everyday lives of informal settlement dwellers in Maputo. Further information available in their website: http://www.homespace.dk/

45. Lewins R, Coupe S, Murray F: Voices from the Margins: Consensus Building and Planning with the Poor in Bangladesh. Rugby: Practical Action Pub; 2007.

46. Evans A, Varma S: Practicalities of participation in urban IWRM: Perspectives of wastewater management in two cities in Sri Lanka and Bangladesh. In Natural Resources Forum: Wiley Online Library: 2009:19-28. 
47. Carolan MS: Sustainable agriculture, science and the co-production of 'expert' knowledge: The value of interactional expertise. Local Environment 2006, 11:421-431.

48. Pohl C, Rist S, Zimmermann A, Fry P, Gurung GS, Schneider F, Speranza Cl, Kiteme B, Boillat $S$, Serrano $E$, et al.: Researchers' roles in knowledge co-production: experience from sustainability research in Kenya, Switzerland, Bolivia and Nepal. Science and Public Policy 2010, 37:267-281.

49. Taş $M$, Taş $N$, Durak $S$, Atanur $G$ : Flood disaster vulnerability in informal settlements in Bursa, Turkey. Environment and Urbanization 2013, 25:443-463.

50. Carmin J, Anguelovski I, Roberts D: Urban climate adaptation in the global south: Planning in an emerging policy domain. Journal of Planning Education and Research 2012, 32:18-32.

${ }^{* *} A$ seminal paper that draws the experience of pioneering cities in bringing forward climate change adaptation agendas.

51. Carmin J, Chu E, Dodman D: Urban Climate Adaptation and Leadership: From Conceptual to Practical Understanding. Paris: OECD Publishing; 2013.

52. Parnell S, Pieterse E, Watson V: Planning for cities in the global South: an African research agenda for sustainable human settlements. Progress in Planning 2009, 72.

53. Cartwright A, Parnell S, Oelofse G, Ward S (eds.): Climate Change at the City Scale: Impacts, Mitigation and Adaptation in Cape Town. Abingdon: Routledge; 2012.

${ }^{* *}$ An inspiring example of interdisciplinary and transdisciplinary efforts to develop a climate change strategy at the city scale.

54. Cabannes Y: Participatory budgeting: a significant contribution to participatory democracy. Environment and Urbanization 2004, 16:27-46. 